\title{
Tecendo possibilidades de confrontar-se com a finitude: um relato sobre atendimento psicológico a familiar em Unidade de Terapia Intensiva
}

\author{
Weaving possibilities to confront finitude: a report on psychological \\ care to family members in an Intensive Care Unit
}

\section{Gabriele Honscha Gomes}

Resumo: A Unidade de Terapia Intensiva (UTI) é um ambiente onde o alto nível tecnológico utilizado para cuidar de pacientes críticos se encontra com a emergência de sentimentos intensos de medo, impotência e desamparo. Os familiares de pacientes internados se deparam com a possibilidade de perda e também necessitam de um olhar cuidadoso pela equipe de saúde, oportunizando um cuidado humanizado. A partir de um relato de experiência, este artigo tem como objetivo relatar e elucidar sobre o trabalho realizado com uma familiar em contexto UTI, propondo reflexões sobre os mecanismos psíquicos de defesa utilizados, as possibilidades suscitadas a partir do acompanhamento psicológico e as formas de inserção da psicologia na equipe multiprofissional. Conclui-se que o trabalho multidisciplinar é potencializado pelo olhar subjetivo e individual da psicologia e que a comunicação entre a tríade equipefamília-paciente é essencial para que o cuidado humanizado aconteça. É a partir do cuidado integrado que é possível atender todas as necessidades dos pacientes e seus familiares, bem como proporcionar um ambiente de acolhimento e continente frente ao impacto causado pelo adoecimento.

Palavras-chave: Psicologia; Cuidados Críticos; Equipe Multiprofissional.

\begin{abstract}
The Intensive Care Unit (ICU) is an environment where the high technological level that is used to care for critically ill patients meets the emergence of intense feelings of fear, impotence and helplessness. Family members of hospitalized patients are faced with the possibility of loss and also need a careful look by the health team, providing opportunities for humanized care. Based on an experience report, this article aims to report and elucidate the work carried out with a family member in the ICU context, proposing reflections on the psychological defense mechanisms used, the possibilities arising from the psychological defense mechanisms used, the possibilities arising from psychological monitoring and the forms of insertion of psychology in the multidisciplinary team. It is concluded that multidisciplinary work is enhanced by the subjective and individual approach of psychology and that communication between the team-familypatient triad is essential for humanized care to happen. It is from integrated care that is possible to meet all the needs of patients and their families, as well as providing a welcoming and continental environment in the face of the impact caused by illness.
\end{abstract}

Keywords: Psychology; Critical Care; Multiprofessional Team.

\footnotetext{
1 Psicóloga; Residente na Residência Multiprofissional do Hospital de Clínicas de Porto Alegre, Programa Adulto Crítico.

E-mail: gabrielehgomes@gmail.com
} 


\section{Introdução}

A relação do indivíduo com a morte, na contemporaneidade, é pautada majoritariamente por uma recusa a esta etapa final do ciclo vital. 0 avanço nas ciências médicas permite que 0 indivíduo permaneça vivo por mais tempo, apesar de acometimentos de saúde graves e necessidade de aparelhos para manter funções de órgãos essenciais para a vida. A Unidade de Terapia Intensiva (UTI) é conhecida pelo alto nível tecnológico disponível para cuidar de pacientes, contudo, também é um local muito associado a altos níveis de estresse e contato intenso com incertezas, dúvidas, medo de perdas e manifestações de sofrimento psíquico (Souza et al, 2018). Algumas particularidades do ambiente configuram-se como possíveis estressores para pacientes e familiares que ali se encontram, como a perda da privacidade, quebra do ciclo sono-vigília, sons emitidos por aparelhos diversos, afastamento da família, submissão a regras e grande rotatividade de profissionais (Marca, Pinho, Impieri \& Rosaes, 2018). 0 morrer em Terapia Intensiva é atravessado por questões biomédicas, familiares, sociais, culturais, religiosas e econômicas, necessitando de uma compreensão global e humanizada daquele sujeito do qual se cuida (Monteiro, Magalhães \& Machado, 2017).

A partir do momento em que um membro do núcleo familiar éinternado nesse ambiente, desencadeia-se uma desorganização na rotina familiar e na sensação de controle sobre a vida, exacerbando angústias e provocando a necessidade de repensar e reorganizar rotinas (Fumis, 2016). Frente a isso, este artigo consiste em um relato de experiência construído a partir de um caso atendido em ambiente de Terapia Intensiva de um hospital-escola público de alta complexidade. Busca-se tecer reflexões sobre a impossibilidade do confronto com a finitude, os mecanismos defensivos utilizados, as possibilidades emergidas a partir do acompanhamento psicológico e do trabalho multidisciplinar. Detalhes que pudessem identificar os sujeitos atendidos foram suprimidos e/ou alterados com vias de garantir o sigilo profissional e anonimato, respeitando assim, as normas éticas necessárias.

\section{O caso e o contexto}

A paciente, 80 anos, internou na UTI devido a falência renal e múltiplas infecções, vindo a necessitar de intubação e ventilação mecânica por período prolongado, bem como hemodiálise. Ela tinha longo histórico de adoecimentos prévios e comorbidades, denotando um avançado processo de senilidade. A inserção da psicologia no caso se deu por meio de consultoria solicitada pela equipe médica ao identificar dificuldades da filha da paciente, 60 anos, em compreender a gravidade do quadro clínico e prognóstico reservado. Também é relatado neste momento que a familiar estava dormindo na recepção do hospital desde que a mãe havia sido admitida na UTI.

0 caso foi atendido no ano de 2020, ou seja, em contexto de pandemia de COVID-19 e de maiores restrições para a circulação de pessoas no hospital. As normas de contingência e segurança frente a pandemia restringiam as visitas de familiares à UTI, podendo comparecer apenas um familiar para a visita diária, que tinha duração de meia hora. Considera-se importante detalhar esse contexto visto o impacto inerente de um maior distanciamento entre familiares e pacientes, com o objetivo de proporcionar maior segurança a todos

\section{Aproximações iniciais}

Nos atendimentos iniciais, ao escutar o relato da filha sobre sua relação com a mãe, era perceptível que essa consistia em uma relação muito próxima e da qual ela se mostrava dependente. Soube-se que ela era filha única e que durante toda a vida ocupou o lugar de cuidadora da mãe, não desenvolvendo aspectos individuais e uma maior independência da relação maternal. Essa relação fazia com que a familiar permanecesse no saguão do hospital durante as noites, pois acreditava que a mãe sentia sua presença e assim, teria mais chances de se recuperar. Não existia, inicialmente, a possibilidade de investigar a rede de apoio familiar existente, entendia-se a partir do relato da filha que apesar de ter uma família grande e do contato frequente dos familiares em busca de notícias, ela não conseguia contar com eles como possíveis recursos de ajuda e amparo naquele momento. Reforçava-se assim, a relação dual entre ela e a mãe, onde não era permitido abrir espaços e lugares para outros. Esse padrão de comportamento podia ser observado ao longo da vida da filha, onde sua rede de relações afetivas era composta exclusivamente pela mãe, não se envolvendo em relacionamentos românticos ou de amizade.

Ao falar da mãe, a familiar apresentava um discurso infantilizado permeado pela idealização desta figura, comportamento esperado durante as fases iniciais da vida de um sujeito, onde ainda não se tem uma diferenciação completa do self para com o outro externo, e onde os pais ocupam um lugar central e idealizado na mente da criança (McWilliams, 2014). A autora citada também relata que a partir da condição idealizada infantil, é esperado que 0 processo de amadurecimento traga um processo inerente de desidealização das figuras parentais, sendo essa uma parte essencial da condição de separaçãa e individuação do sujeito. A relação adulta da filha com a mãe, portanto, era pautada por uma idealização total e dependência, onde a mãe ocupava um lugar de perfeição e o processo de individuação parecia não ter acontecido.

Como parte das entrevistas iniciais feitas na psicologia em contexto hospitalar, é de suma importância investigar e compreender qual era o papel do paciente adoecido dentro do contexto familiar. Éa partir desta compreensão que se pode entender o que significa este adoecimento dentro daquele núcleo familiar subjetivo, e o que está sendo de fato perdido (Almendra \& Itapary, 2018). Neste caso, a partir da relação dependente entre mãe e filha, entendeu-se que a ideia de falecimento da mãe trazia um confronto com 0 vazio, não existindo outros vínculos afetivos que pudessem ocupar o lugar que estaria sendo desocupado.

Observou-se também um forte sentimento de culpa da filha frente ao adoecimento da paciente, destacando-se diversas falas suas sobre acreditar que poderia ter feito mais pela mãe e que todos os cuidados despendidos não haviam sido suficientes, tornando-a uma filha ruim. Os sentimentos de culpa frente 0 contexto de adoecimento e internação são considerados esperados, junto de sentimentos como frustração, arrependimento, raiva, revolta, ansiedade, medo, impotência, fragilidade e desamparo (Amendoeira, Soares \& Mussoi, 2018).

Era perceptível um grande investimento da filha na saúde da mãe, levando-a a um número excessivo de médicos, realizando múltiplos examese buscando controlar todos os sinais de possíveis acometimentos de saúde que a mãe pudesse apresentar. Além disso, notou-se uma dificuldade da filha em ver a morte como processo natural e indissociável da vida, existindo a crença de que a mãe não iria vir a falecer nunca. Apresentava uma ideia de controle onipotente, de que os seus cuidados seriam capazes de driblar a morte. 
Essas características foram sendo percebidas principalmente nos momentos de notícias médicas, onde as informações clínicas são transmitidas aos familiares pela equipe médica e onde ocorrem as maiores trocas entre o profissional e a família do paciente internado. A comunicação de más notícias em ambiente de UTI pode-se configurar em um momento de notícias repentinas e abruptas, que causam uma ruptura na homeostase do núcleo familiar a partir da imposição de uma nova realidade que precisa ser assimilada. A dimensão do inesperado traz sentimentos de angústia, desamparo e grande sofrimento psíquico, podendo ser conceituado como uma situação traumática (Monteiro et al, 2017). No caso aqui discutido, a paciente já apresentava acometimentos de saúde prévios, múltiplas internações e comorbidades importantes, no entanto, observou-se que a familiar recebia as notícias de gravidade e prognóstico reservado com surpresa, causando uma desorganização psíquica. Antes das conversas com a equipe médica, as temáticas de envelhecimento e morte não eram parte do seu dia a dia e o trabalho de negação operava como defesa psíquica, evitando que esses pensamentos pudessem se tornar conscientes.

Avaliou-se, neste momento, que a familiar apresentava um sofrimento emocional intenso e não dispunha de recursos psíquicos protetivos que pudessem the auxiliar no enfrentamento do adoecimento da mãe de forma mais adaptativa. Ela se defrontava com sentimentos de desamparo e frustração frente à falta de controle dos processos de adoecimento e envelhecimento, negando-os e se colocando resistente frente às falas da equipe que sinalizavam esses aspectos. Almendra e Itapary (2018) trazem que esses comportamentos considerados excessivos e desadaptativos aparecem em contextos onde 0 sujeito vivencia uma situação-limite, que ultrapassa aquilo que consegue manejar de forma satisfatória, culminando em um sofrimento psíquico desorganizador.

\section{A equipe e ações terapêuticas}

Para além do trabalho psicológico, que se deu em atendimentos individuais com a familiar, é importante a reflexão sobre a inserção da psicologia nas discussões multidisciplinares com a equipe que compõe o cuidado em UTI. Em revisão bibliográfica sobre o trabalho do psicólogo em UTI, Vieira e Waischunng (2018) concluem que a presença da psicologia nas equipes de saúde pode servir como fomentadora do trabalho multidisciplinar, promovendo um cuidado mais integral e humanizado a pacientes e familiares. Melo e Nonato (2018) trazem que o trabalho multidisciplinar diz respeito a uma prática onde as diversas áreas do saber compartilham conhecimentos e perspectivas com 0 objetivo de construir um cuidado humanizado para o paciente e sua família.

Inicialmente, observou-se uma contratransferência negativa por parte da equipe médica. A familiar apresentava um comportamento bastante questionador, exigindo constantemente explicações e comprovações em exames sobre o que era relatado, bem como propunha soluções mágicas que encontrava em leituras da Internet, acreditando que essas condutas pudessem salvar a mãe. Compreendendo esse contexto de maior dificuldade no manejo, procurou-se sensibilizar os profissionais assistentes para o sofrimento psíquico intenso e falta de recursos emocionais da familiar, que naquele momento indicavam que ela não conseguia tolerar a realidade que se impunha. Buscou-se a inserção da psicologia nos rounds multiprofissionais, prática que consiste em um momento onde membros da equipe multiprofissional discutem os casos dos pacientes internados à beira leito e decidem planos de condutas e de tratamento. Barbosa et al (2020) traz que o uso do round consiste em um facilitador da comunicação entre membros da equipe, bem como permite uma ampliação da discussão do caso para além de um olhar unicamente biomédico, conseguindo promover um cuidado integral que busque atender todas as necessidades do paciente e de seus familiares.

Da mesma forma como a comunicação entre membros da equipe é importante para a qualificação da assistência em saúde, a comunicação entre equipe e familiares também é essencial. 0 momento de notícias médicas é um momento de extrema importância ao considerar que é a partir desses diálogos que serão construídos os vínculos entre equipe e família. Puggina et al (2014) relatam que este vínculo torna-se terapêutico ao passo que os familiares desenvolvem confiança nos profissionais, sentindo-se ajudados e percebendo a assistência prestada como cuidadosa e respeitosa. Esta mesma pesquisa elencou as principais necessidades dos familiares que acompanhavam pacientes na UTI, identificando a necessidade de segurança como a mais importante. Esta necessidade consistia na compreensão do quadro clínico e prognóstico do paciente, disponibilidade de informações claras sobre os cuidados prestados, rotinas da UTI e orientações sobre as formas como 0 familiar poderia contribuir com esse cuidado.

Esta necessidade deve ser trabalhada no momento das notícias médicas, sendo importante a reflexão e a compreensão de que esse diálogo é visto pela família como essencial e é o momento oportuno onde dúvidas e angústias podem circular. Fumis (2016) discute sobre como a possibilidade de compreensão dessas notícias médicas vai além das capacidades cognitivas e do nível de escolaridade do familiar, visto que os sentimentos intensos suscitados no contexto de crise podem prejudicar a capacidade do sujeito de compreender as informações recebidas. Desta forma, é preciso pensar e aprimorar a comunicação da equipe para com a família, elencando formas como esta pode ser mais eficaz e humanizada, acolhendo aquele familiar em sofrimento psíquico e conseguindo, a partir disso, comunicar de forma clara e sensível, notícias que muitas vezes são ruins. Ao participar da comunicação médica, o olhar subjetivo e humanizado da psicologia pode contribuir avaliando se esses aspectos estão sendo comunicados e explicados.

Como estratégias para comunicação com familiares, Farias e Saboya (2018) escrevem sobre a importância de atentar para o local onde se dá a conversa, dando preferência para locais tranquilos que garantam privacidade ao momento, deve-se evitar 0 uso excessivo de jargões e termos técnicos, transmitindo as informações médicas e prognóstico, mas deixando espaço para a esperança e, por fim, respeitar o ritmo de cada familiar com quem se conversa. Em relação a esse respeito ao ritmo do familiar, os autores trazem 0 exemplo da negação como mecanismo de defesa que, em al guns momentos, é necessário para o indivíduo suportar aquele contexto, sendo importante que a equipe possa avaliar caso a caso e permitir que o familiar utilize das ferramentas psíquicas que possuí, compreendendo o quanto e a forma de notícias aquele sujeito suporta naquele momento.

Buscou-se, então, a participação junto das comunicações de notícias médicas que se davam posteriormente ao horário de visita na unidade, buscando facilitar a comunicação entre a familiar e profissional e oportunizando suporte emocional à ela. A literatura traz como função do psicólogo a busca pela viabilização e aprimoramento da comunicação entre a tríade equipe-família-paciente, podendo o profissional auxiliar nesses processos de compreensão e esclarecimentos, entendendo a comunicação efetiva como parte essencial do trabalho em saúde (Vieira \& Waischunng, 2018)

Compreendeu-se que a resistência da familiar em deixar o hospital era em decorrência de sua fragilidade psíquica e dificuldade de dar conta das 
sobrecargas de demandas emocionais vivenciadas. Ir para casa fazia com que entrasse em contato com a ausência da mãe, o que não era possível ser acessado e elaborado. Em pesquisa referente a bibliografia produzida a respeito dos atendimentos a familiares de pacientes internados em UTI, vemos que uma das principais fontes de sofrimento vivenciados pelos familiares é a descontinuidade da rotina cotidiana, onde novos papéis e atribuições precisam ser desempenhados e adaptações realizadas (Fontes, 2018). Refletindo a respeito dessas mudanças que se colocam de forma abrupta na vida familiar, o retorno para a casa sem o paciente pode ser visto como um momento onde a realidade de perda se concretiza, onde a ausência do paciente em casa é vista como um futuro possível e permanente.

Durante os atendimentos, buscou-se iniciar um processo de sensibilização da importância de manter aspectos essenciais do autocuidado, como higiene, alimentação e sono. A dificuldade no autocuidado é identificada como esperada dentro desse contexto, onde a atenção do familiar se volta aos cuidados e preocupações com o paciente, não conseguindo dar conta de também prestar atenção em si (Monteiro et al, 2017), contudo, neste caso, essa dificuldade era exacerbada e tornava-se desadaptativa, necessitando de intervenções.

Com o desenvolvimento de um vínculo terapêutico, a familiar pode utilizar o espaço de atendimento para refletir sobre essas questões, confiando na equipe assistente o cuidado de sua mãe e se permitindo ir para casa algumas, mesmo que poucas, vezes. Frente à impossibilidade de contar com uma rede de apoio externa ao hospital naquele momento, reflete-se que a equipe muitas vezes precisou ocupar um lugar de ego auxiliar para a familiar. Marca, Pinho, Impieri e Rosaes (2018) fazem uso dos conceitos de holding e handling teorizados porWinnicott como parte do trabalho do psicólogo nesse contexto de apoio egóico aos familiares e pacientes.

\section{Encontrando espaço para possibilidades}

A familiar se mostrou bastante demandante de atendimentos psicológicos, que estavam sendo realizados quase diariamente durante e após 0 horário de visita à UTI. Observou-se que a manutenção do vínculo terapêutico e confiança de que o espaço de atendimento era seguro e propício para pensar sobre as dificuldades enfrentadas naquele momento, tornou possível à familiar começar a ouvir as notícias médicas, bem como acessar o medo da morte e o que significava para ela a perda da mãe. A dificuldade de assimilar informações fornecidas pela equipe médica se mostrou persistente, contudo, nos atendimentos era possível revisitar aquilo que havia sido dito com mais calma e continência.

Percebeu-se que a familiar utilizava de defesas primárias e imaturas, apresentando maior fragilidade emocional e facilidade de se desorganizar psiquicamente frente a imposição de uma realidade diferente da realidade do seu ideal. Laplanche e Pontalis (2001) trazem o conceito de defesa psicanalítica como o "conjunto de operações cuja finalidade é reduzir, suprimir qualquer modificação suscetível de pôr em perigo a integridade e a constância do indivíduo biopsicológico" (p. 107). Esses processos se dão de forma inconsciente e, a partir dos processo defensivos observados durante os atendimentos a esta familiar, observa-se principalmente o uso de defesas como a negação, 0 controle onipotente e a idealização, já citada anteriormente.

As defesas, principalmente as primárias, iniciam-se na fase pré-verbal do desenvolvimento como respostas esperadas naquela faixa etária para controle da angústia. Ou seja, inicialmente o uso de defesas é algo inerente e essencial para o desenvolvimento psíquico do bebê, tornando-se representações de patologias e dificuldades no momento em que persistem para além da infância, não sendo amadurecidas e transformadas em formas de defesa mais complexas (McWilliams, 2014).

0 controle onipotente é percebido no discurso da familiar quando essa se mostra desorganizada e imersa em uma angústia extrema ao entrar em contato com a sua impotência e falta de controle sobre o mundo externo. As defesas que a familiar utilizava ao longo de sua vida até aquele momento, vinham dando conta de manter essas temáticas fora de seu consciente, contudo, a realidade de um contexto de adoecimento se impõe de forma imperativa, eas defesas narcísicas que operaram ao longo da vida do sujeito não conseguem mais dar conta de evitar e proteger o indivíduo do contato com a dor e com 0 sofrimento psíquico (Dias, Pereira \& Rodrigues, 2018). 0 contexto vivenciado em ambiente de UTI faz com que familiares se defrontem com sua impotência e com os limites inerentes a um processo de envelhecimento e adoecimento, sobre o qual não se tem controle e muitas vezes não se consegue alterar o curso de agravamento, não podendo driblar a finitude (Pinho \& de Marca, 2018).

0 reconhecimento de que existiam limites sobre o que a ciência era capaz de dar conta, bem como os limites individuais da familiar foi algo trabalhado durante os atendimentos. Buscou-se sensibilizá-la de que ela havia feito tudo que estava ao seu alcance, e talvez mais, durante os anos que ficou como responsável pelos cuidados da mãe. 0 pensamento de que apesar de ter despendido todas suas ferramentas e boa parte da sua vida para cuidar da mãe, e que ainda assim estava precisando se confrontar com a possibilidade de perdê-la, era parte importante do seu sofrimento psíquico.

Com o tempo, também pode-se flexibilizar e expandir a compreensão sobre a rede de apoio familiar. Inicialmente, o discurso era fechado na certeza de que não existia uma rede de apoio com a qual ela pudesse contar, não permitindo que fosse feito contato com esses familiares a fim de solicitar auxílio. 0 desenvolvimento desse aspecto foi construído em conjunto com o Serviço Social, e pôde-se sensibilizar a familiar da importância de poder solicitar e receber ajuda, bem como de contar com seus familiares com auxílio na locomoção entre sua residência e o hospital. Entende-se que a ausência de rede de apoio nesses momentos pode ser um indicativo de conflitos familiares prévios, que se exacerbam em decorrência da emergência de um estressor (Monteiro et al 2017).

\section{O confronto com a finitude}

0 quadro clínico da paciente foi aos poucos se deteriorando, não respondendo às medidas instituídas e fazendo com que as discussões nos rounds multiprofissionais se dessem de forma a pensar em estratégias para comunicar e preparar a filha para um óbito iminente. Conjuntamente, entendeu-se a necessidade de envolver outros familiares, frente a avaliação de que a filha poderia não conseguir dar conta sozinha das questões burocráticas e emocionais relacionadas a o falecimento da mãe. Assim, a partir do vínculo construído ao longo dos atendimentos, foi acordado com ela que se faria contato com os familiares para comunicá-los do contexto e deixá-los de sobreaviso frente um possível óbito. 0 contato foi feito pela psicóloga e esse permitiu uma melhor compreensão do contexto familiar no qual mãe e filha faziam parte. Havia uma rede de apoio que se preocupava e buscava estar presente, contudo, devido a relação simbiótica e dependente entre elas, não era permitido que 
outros familiares ocupassem também um lugar de cuidado e preocupação. Um dos objetivos da intervenção psicológica nesse momento foi auxiliar a filha a expandir sua rede afetiva, criando espaços e possibilidades de amparo externos ao hospital. Monteiro, Rutherford e de Paula (2018) pontuam como essencial a presença de rede de apoio em momentos de estresse exacerbado, sendo parte importante das condições de manejo e elaboração das vivências.

Com 0 agravamento do quadro clínico, avaliou-se que a familiar não conseguia mais negar as informações trazidas pela equipe médica, o que intensificou seu sofrimento psíquico, mas também permitiu que se fizesse espaço para pensar sobre a terminalidade da mãe. Ela conseguia refletir sobre o que significava a morte da mãe e sobre os sentimentos decorrentes deste pensamento. Esse processo foi percebido como oscilante e ambivalente e essa ambivalência é vista pela literatura como uma característica inerente aos processos de luto e luto antecipatório, onde é por meio desse movimento que o sujeito consegue uma elaboração racional e emocional do contexto vivenciado (Monteiro, Rutherford \& de Paula, 2018).

É importante a reflexão sobre o papel da esperança no discurso de familiares de pacientes em UTI. A esperança é parte inerente das reações psíquicas esperadas no contexto de adoecimento, devendo ser avaliada de forma subjetiva, para que se possa entender se a esperança está atuando de forma protetiva ou desadaptativa para aquele indivíduo. É preciso um equilíbrio e um estado de movimentação entre os polos de contato com a realidade da morte e espaços onde se pode pensar em esperança, sendo esse um fator essencial para que o familiar consiga, diariamente, comparecer ao hospital e se defrontar com o paciente adoecido (Ferreira \& Mendes, 2013). A esperança faz com que estar em um ambiente permeado por notícias desesperançosas seja mais tolerável, e é justamente esse movimento entre pólos que se busca proporcionar a partir do atendimento psicológico em UTI.

Entre esses discursos ambivalentes, foi acordado com a equipe médica assistente de que seria registrado em prontuário os telefones de duas familiares, elencadas pela filha da paciente como aquelas das quais era mais próxima, para que pudessem ser acionadas em caso de óbito. Frente a imprevisibilidade, pensou-se ser essa a melhor forma de amparar a filha e ter mais segurança de que ela não estaria sozinha no momento da notícia de óbito, caso esse viesse a acontecer fora do horário de plantão dos profissionais rotineiros.

\section{Movimentos de despedida}

No último atendimento psicológico realizado antes do falecimento da paciente, a familiar pode falar sobre sua confiança na fé religiosa e como acreditava que Deus iria escolher o melhor caminho para a mãe. Esse discurso sintetizou a compreensão interna de que ela reconhecia não ter total controle sobre o futuro e indicou aos profissionais que ela compreendia a iminência do óbito, conseguindo se colocar no movimento do processo de luto antecipatório. Monteiro, Magalhães e Machado (2017) trazem a religião como um fator importante no processo de luto, podendo ser uma forma de enfrentamento positiva e adaptativa, auxiliando os familiares a manejar sentimentos de desamparo e impotência perante a imprevisibilidade da vida.

Neste momento, a familiar também trouxe uma lembrança para os membros da equipe assistente que vinham acompanhando seu caso de forma mais próxima, simbolizando uma despedida. Ferreira e Mendes (2013) discutem sobre a relevância da assistência psicológica em casos de iminência da morte em ambiente de UTI, trazendo que mesmo para aqueles familiares que apresentam dificuldade de aceitação desse contexto, é possivel utilizar do espaço de atendimento para pensar a temática do morrer, o que as autoras consideram como uma forma de preparação psicológica para esta realidade.

Muniz e Silveira (2020) inferem que o trabalho do psicólogo em UTI se dá a partir da pontuação de um olhar diferente do olhar biomédico, trazido pelas outras especialidades. Ao inserir um outro olhar, pode-se pontuar diferentes questões e diferentes necessidades do paciente e familiares, promovendo um cuidado integral e humanizado que conta com as subjetividades e particularidades dos sujeitos.

0 papel do psicólogo em um momento de desorganização, desacomodação das certezas e quebra da ideia de que o sujeito possui controle sobre seu entorno, é ocupar um lugar de continência frente a fragilidade e vulnerabilidade do outro. É conseguir nomear e facilitar que a palavra circule sobre temáticas muitas vezes temidas e evitadas. Para Almendra e Itapary (2018) 0 adoecer é uma experiência da perda de lugar, uma experiência que traz de forma inerente processos de perdas e processos de lutos, sendo função da psicologia ter um olhar para a subjetividade, auxiliando no pensar de novos lugares possíveis, de ressignificações.

\section{Considerações finais}

Este trabalho buscou relatar sobre um vínculo psicoterapêutico construído em ambiente de Terapia Intensiva. Buscou refletir sobre a importância do psicólogo neste ambiente e os laços multidisciplinares construídos e avaliados como essenciais para fornecer um espaço seguro e continente, onde pode-se construir caminhos e possibilidades. Tecer espaços de afeto em um ambiente conhecido por sua gravidade e dureza é papel do psicólogo hospitalar. 0 profissional também se propõe a facilitar a comunicação entre família e equipe, buscando sensibilizar ambas as partes sobre as interfaces e desafios existentes nesse diálogo, sobre as limitações de cada um e formas como cada sujeito consegue dar conta da confrontação com a morte e com a perda.

0 ambiente de Terapia Intensiva, como descrito anteriormente, é um ambiente tecnológico, dinâmico e especializado, onde a humanização se dá justamente ao unir esses saberes e características com um olhar individual para cada sujeito ali presente, um olhar de cuidado e acolhimento, garantindo respeito cultural e ético (Lazzari, Oliveira \& Caddah, 2018). Os autores descrevem que a humanização é para além do cuidado centrado no paciente, mas é uma postura de dar lugar a falas, sejam essas do paciente, da família ou de outros membros da equipe. É o estabelecimento de uma comunicação eficaz, acolhedora e disponível.

A psicologia conta com ferramentas de escuta essenciais para tornar uma experiência potencialmente traumática em uma experiência de cuidado, sendo continente para as angústias e subjetividades de cada um. A psicologia isolada, contudo, não dá conta da complexidade de um atendimento em UTI, sendo preciso de uma equipe aberta ao trabalho conjunto, empática com o sujeito que está ali presente e compreensiva de que aquele sujeito é mais do que um corpo e é mais do que um familiar cheio de dúvidas e questionamentos. 


\section{Referências}

Almendra, F. S. R \& Itapary, M. (2018). Da urgência médica à subjetiva | A responsabilidade da instituição e a responsabilidade de cada um. In: Almendra, F.S. R. (Eds.) Psicologia em Unidade de Terapia Intensiva: intervenções em situações de urgência subjetiva. (pp. 35-47) São Paulo: Atheneu

Amendoeira, L. M.; Soares, B. S. R. \& Mussoi, P. M. G (2018).Considerações sobre 0 atendimento da psicologia no Instituto Nacional de Traumatologia e Ortopedia. In: Almendra, F. S. R. (Eds.) Psicologia em Unidade de Terapia Intensiva: intervenções em situações de urgência subjetiva. (pp. 47-61) São Paulo: Atheneu

Barbosa, R. V., Lopes, M. Á. C. P., Pacheco, G. M., Pinto, J. I. D. S., Monteiro, Y. F. B., da Costa Pinto, S., Monteiro, K. C. G. \& da Silva, J. G. (2020). Benefícios do round multidisciplinar na unidade de terapia intensiva. Brazilian Journal of Health Review, 3(6), 17989-18001. doi: :10.34119/bjhrv3n6-203

Farias, C. C. P. \& Saboya, F. (2018). Sofrimento do paciente, da família e da equipe. In N. Azevedo, E. Aquim \& A. Santos, (Eds.) Assistência ao paciente crítico: uma abordagem multidisciplinar. (pp. 281-289) São Paulo: Atheneu.

Ferreira, P. D., \& Mendes, T. N. (2013). Família em UTI: importância do suporte Psicológico diante da iminência de morte. Revista da SBPH, 16(1), 88-112. Recuperado de:http://pepsic.bvsalud.org/scielo.php?script=sci_arttext\&pid $=\$ 1516-08582013000100006 \& \operatorname{lng}=$ pt\&ting $=p t$.

Fontes, M. (2017). A psicologia hospitalar e a contribuição do psicólogo junto a família dos pacientes internados em uma Unidade de Terapia Intensiva Adulto (Graduação). Centro Universitário Luterano de Palmas (CEULP/ ULBRA). Recuperado de: https://ulbra-to.br/bibliotecadigital/uploads/ document5e1e0d97abb4a.pdf.

Fumis, R. R. L (2016) A família do paciente crítico. In: Padilha, R. Q \& Fumis, R. R. L. (Eds.) UTI Humanizada: cuidados com o paciente, a familia e a equipe. São Paulo: Atheneu

Dias, M. S. F. M; Pereira, F. R. C \& Rodrigues, D. R. S (2018). Urgência subjetiva e impasses narcísicos em Unidade de Terapia Intensiva Pediátrica. In: Almendra, F. S. R. (Eds.) Psicologia em Unidade de Terapia Intensiva: intervençōes em situações de urgência subjetiva. (pp. 13-23) São Paulo: Atheneu

Laplanche, J., \& Pontalis, J. (2001). Vocabulário da Psicanálise (4th ed.). São Paulo: Martins Fontes.

Lazzari, C; Oliveira, J. M. \& Caddah, T. (2018). Confiança no acolhimento: percepção da tríade paciente-família-equipe assistencial. In: N. Azevedo, E. Aquim and A. Santos, (Eds.), Assistência ao paciente crítico: uma abordagem multidisciplinar. (pp. 327-337) São Paulo: Atheneu.

Marca, J. V. F; Pinho, M. C. M. S; Impieri, J.V \& Rosaes, P. A. L. (2018). Um caso de síndrome de encarceramento In: Almendra, F. S. R. (Eds.) Psicologia em Unidade de Terapia Intensiva: intervenções em situações de urgência subjetiva. (pp. 61-73) São Paulo: Atheneu

McWilliams, N. (2014). Processos defensivos primários. In: McWilliams, N. Diagnóstico Psicanalítico (pp. 121-148) (G. W. Linck, Trad). Porto Alegre: Artmed (Obra original publicada em 2011).

Melo, C., \& Nonato, L. (2018). Comunicação efetiva, trabalho em equipe e cuidado centrado no paciente. In N. Azevedo, E. Aquim \& A. Santos (Eds.) Assistência ao paciente crítico: uma abordagem multidisciplinar. (pp. 295303) São Paulo: Atheneu.

Monteiro, M. C; Rutherford, C. M \& de Paula, S. T. C. (2018).Perdas e luto: repercussões para paciente, família e equipe. In: Almendra, F. S. R. (Eds.) Psicologia em Unidade de Terapia Intensiva: intervenções em situações de urgência subjetiva. (pp. 109-119) São Paulo: Atheneu

Monteiro, M. C., Magalhães, A. S., \& Machado, R. N. (2017). A morte em cena na UTI: a família diante da terminalidade. Trends in Psychology, 25(3), 1285-1299. doi: 10.9788/TP2017.3-17Pt

Muniz, M. S., \& Silveira, B. B. (2020). Atuação da Psicologia em Unidades de Terapia Intensiva. Revista Mosaico, 11(2), 95-100. doi: 10.21727/ rm.v11i2.2256
Pinho, M. C. M. S \& de Marca, J. V. F (2018). Quando o coração expressa a dor do indizível. In: Almendra, F. S. R. (Eds.) Psicologia em Unidade de Terapia Intensiva: intervenções em situações de urgência subjetiva. (pp. 97-109) São Paulo: Atheneu

Puggina, A. C., lenne, A., Carbonari, K. F. B. S. D. F., Parejo, L. S., Sapatini, T. F., \& Silva, M. J.P. (2014). Percepção da comunicação, satisfação e necessidades dos familiares em Unidade de Terapia Intensiva. Escola Anna Nery, 18(2), 277-283. doi: 10.5935/1414-8145.20140040

Souza, A., Trevisan, F., Lucin, G., Casagrande, L., Caruso, L., de Oliveira, L., Maturana, M., de Faria, M. and Prieb, R., 2018. Admissão do paciente crítico. In: N. Azevedo, E. Aquim and A. Santos, (Eds.), Assistência ao paciente crítico: uma abordagem multidisciplinar. (pp. 7-17) São Paulo: Atheneu.

Vieira, A. G., \&Waischunng, C. D. (2018). A atuação do psicólogo hospitalar em Unidades de Terapia Intensiva: a atenção prestada ao paciente, familiares e equipe, uma revisão da literatura. Revista da SBPH, 21(1), 132-153. Recuperado de http://pepsic.bvsalud.org/scielo.php?script=sci_arttext\&pid=\$1516-08582018000100008\&lng=pt\&tlng=pt. 